\title{
Peer Mentoring for Women in STEM
}

\section{Prof. Sinéad C Mac Namara, Syracuse University}

Sinéad Mac Namara is a structural engineer and Associate Professor teaching in both the School of Architecture and the College of Engineering of Syracuse University. She studied civil and structural engineering at Trinity College Dublin and Princeton University. Her research is concerned with structural art, shell structural design, alternate pedagogies for interdisciplinary education, and investigations to foster creativity and innovation in engineering curricula. Mac Namara co-authored a book Collaboration in Architecture and Engineering released in 2014 and her research has been published in engineering and architecture education journals, nationally and internationally. She has received awards for innovative teaching from Princeton University, Syracuse University, and the American Society for Engineering Education. She also engages in design and design-build projects as a collaborator with her architecture students and colleagues. This work has been recognized with awards from the Association of Collegiate Schools of Architecture, the Architectural Institute of America and the City of New York.

\section{Ms. Anne E Rauh, Syracuse University}

Anne E. Rauh is the Head of Collections and Research Services at Syracuse University Libraries. She leads the collection activities, the subject liaison work, and the university aligned research initiatives of the Libraries. She holds a B.A. in International Studies and a M.A. in Library and Information Studies, both from the University of Wisconsin-Madison. Anne is an active member of the American Society for Engineering Education and the Eastern New York Chapter of Association of College and Research Libraries. She has presented and published extensively on science and engineering librarianship and university research reputation. Her research interests include collection development, scholarly impact, research services, and publishing and scholarly communication.

\section{Dr. Michelle M Blum, Syracuse University}

Dr. Blum is interested in research in improving undergraduate engineering education; including development of inquiry based activities for first year engineering courses, improvement of student design projects, hands-on activities, professional skills development and inclusion and outreach activities. Dr. Blum also specializes in high performance materials development and characterization for tribological (friction and wear), structural, and biomedical applications.

\section{Dr. Natalie Russo, Syracuse University \\ Dr. Melissa A Green, Syracuse University \\ Prof. Shikha Nangia, Syracuse University}




\section{Peer Mentoring for Women in STEM}

In 2013 a group of female junior faculty and professional staff affiliated with STEM fields at Syracuse University attended an honorary lecture by Mimi Koehl, UC Berkeley, which covered both academic topics and a description of a peer mentoring group which she had been part of for many years. The attendees were inspired to convene a peer mentoring group as Koehl described and as outlined in the book Every Other Thursday: Stories and Strategies from Successful Women Scientists by Ellen Daniell[1].

The group has a stable membership of ten women in the fields of aerospace engineering, architecture, biology, chemical engineering, chemistry, civil engineering, library science, mechanical engineering, physics, and psychology. At the outset, the group's members were assistant professors on tenure track, assistant teaching professors, and assistant librarians. The group now consists of tenured professors, associate professors, librarians, and two of the University's first teaching professors that have been promoted to the associate level.

This paper will explore best practices for forming and maintaining similar peer mentor groups. Topics covered will include group composition, meeting structure, process for new membership, and group expectations. Themes that the group has grappled with include teaching strategies at various scales in STEM, mentoring graduate students and postdoctoral researchers, cultivating healthy relationships with colleagues and collaborators, navigating university politics as women in STEM, optimizing service commitments, achieving work-life balance, and developing and executing institution- and position-specific strategies for career advancement. The paper will reflect on the outcomes and the role of the group as a critical strategy to foster a supportive work environment.

\section{Introduction and Literature Review}

Despite efforts to increase the number of women in STEM fields in general and in academia more specifically, there is still a large gender imbalance. While women are more likely than ever to enter most STEM fields at the undergraduate level[2], the number of women who go into academic positions and then climb the academic ranks is rather dismal. As reported by Smith[3], a 2014 NSF report focused on R1 institutions, found that there were $38 \%$ of women at the Assistant, 15\% at the Associate and only $8 \%$ at the Full Professor level across 6 stem fields that included Biology, Chemistry, Civil and electrical engineering, math and physics. This suggests we need to recruit and retain female assistant professors, but crucially we also need to consider barriers to the successful promotion of women. The success of women in STEM fields has a positive impact not only on women but on men as well.

By the time women reach the point where they are in a tenure-track position in a STEM field, they have already overcome the systemic, pervasive and repetitious gender barriers that exist between being interested and dedicated to a STEM field and successfully graduating from a $\mathrm{PhD}$ program. These barriers are well documented in the literature and include: perceptions that women are not as capable as men in scientific fields; the fact that certain fields are maledominated; and frequent experiences of discrimination, bias, difficult campus culture and negative classroom experiences[4], [5]. 
Our group members' own experiences align all too well with the research findings in this area. The following examples (among others cut for space) were elicited within 20 minutes of an email by one of the authors soliciting group members' experiences. Two different group members, in different graduate programs and fields relayed being told that they received a prestigious NSF GRFP award solely because they were women. Another group member vividly recalls sitting behind a male classmate who wrote "Your Future Boss" on the back of his name placard for her to see. A fourth group member reported a phone call from a student's father in her first year of teaching demanding to know what "some architect woman" was doing teaching his son's civil engineering course. In a particularly egregious example, one member relayed a case of sexual harassment early in her graduate career. After standing up for her rights and receiving written support from the upper administration, she was told to cease and desist by lawyers, threatened with a defamation case by the faculty member who had harassed her, and was ultimately forced to write an apology to this faculty member after the university decided to withdraw their support. It might reasonably be assumed that those women who make it as far as a tenure track appointment have fostered enough resilience to succeed going forward. But, in spite of resilience, or perhaps as a result of this perpetual need to remain resilient, the number of women in full professor positions is still low.

Recent work suggests that Faculty Learning Communities (FLC's), an intervention that provides a space for female faculty to meet regularly to foster the development of knowledge sharing, peer mentoring and support have been shown to be effective in improving faculty retention, advancement and professional growth. Specifically, O'Meara, Nyunt, Templeton, and Kuvaeva assessed retention and promotion for faculty who were and were not involved in FLC's at 5 different land grant institutions[6]. They found that $17.9 \%$ of faculty not involved in FLC's left the university, compared to $6 \%$ of faculty involved in FLCs. Further, 28.9\% of non-participants were promoted (from assistant to associate, or from associate to full) compared to $36.7 \%$ of those who participated. While not an institutionally supported entity, the group described in this paper is in many ways akin to this Faculty Learning Community and was facilitated by Syracuse University's NSF funded Project ADVANCE grant.

The group was started in 2013 after Dr. Mimi Koehl, University of California-Berkeley was invited to Syracuse University to present the Norma Slepecky Lecture. Additionally, during her campus visit, Dr. Koehl facilitated a discussion about her experiences in a peer mentoring group that had been active since the 1970s. This group was profiled in the book Every Other Thursday: Stories and Strategies from Successful Women Scientists [Daniell], and while Dr. Koehl was not the author of the book, she was a founding member of the peer mentoring group. After Dr. Koehl's campus visit, two founding members of the Syracuse University group were inspired to recreate the peer mentoring experience outlined in Every Other Thursday. They reached out to nine additional early career faculty whom they had met during faculty orientation activities, many of whom had also participated in the 2013 discussion, with an initial invitation to join the group.

\section{The Every Other Thursday Model}

The book, Every Other Thursday: Stories and Strategies from Successful Women Scientists[1], tells the inspiring story of a group of women scientists who designed a bi-monthly professional and social gathering to aid each other in navigating through the pressures and complexities of 
their competitive scientific and professional careers. Since the group began in the 1970s, the seven founders were among the first and/or only females in their departments or organizations. The goal of the group was to connect women with shared experiences and concerns, who might otherwise feel isolated at their jobs, and to develop a community of primarily professional, but also social support. The power and longevity behind the group came from the organized agenda and established rules for how the group proceeded each meeting. This ensured that "work" was continually accomplished and it never dissolved into pure social meetings or gossip. The book provided stories of members navigating their careers, and examples of how the group provided advice and support. Finally, the book provided practical guidelines and tips for others who wished to start groups of their own. It is from these guidelines that the group at Syracuse University was established.

\section{Our Adopted Rules}

Much of the structure and process used in our peer mentoring group follows that presented in the book. Every other week, "Group" meets at the home of one member. Partners and family members may be present elsewhere in the home, but only very rarely interact with Group, and even then, in very limited ways (a quick hello at the beginning or the end). Meetings are on the same day of the week at the same time, and are almost never shifted to accommodate temporary schedule changes. There is an understanding that the structured meeting will begin at the prescribed time, and those who have to arrive late know that they will join the meeting midprogress. Snacks and drinks are served, but the collective expectation is that the host went to the grocery store and then put those things on the table (as opposed to more laborious catering).

There is an identified leader of each meeting (usually, but not necessarily, the home host). The host will start the meeting with an invitation to share "paranoias and held feelings." This portion of the meeting is a call to discuss any interpersonal issues internal or external to Group that are keeping any member from honestly sharing information, or effectively working. While not utilized often, this step has been necessary and effective to make sure members are communicating effectively and feel secure when discussing complicated topics.

After the call for "paranoias and held feelings," the host then asks who wants to "work" that meeting. Those bringing an issue to discuss and work through are required to identify themselves, and to ask for a certain amount of time. One of the main meeting responsibilities of the host is to time each person after they begin their work, and to stop the discussion or ask if the working member wants more time when it is up. It is always an option to add more time, but again, a specific amount of time is added to the clock. This rule has proved to be valuable in terms of a check on whether the discussion is still on track and constructive, while conversely, members are always encouraged to "ask for the time you need."

When the host has collected the list of who in Group will work that evening, work begins with a volunteer from the list. The working member usually starts by declaring what they "need" from Group that meeting. This can be: an opportunity to vent without any feedback; specific advice; language for a difficult upcoming email or conversation; a check on how the member handled an interaction that already happened; accountability for homework the member plans to do in the future; or an update on previously declared homework. The working member also mentions the 
level of confidentiality of the topic. Following that, the working member uses their time to explain the situation and ask specific questions of other members. During the explanation, other members are expected to interrupt only in the case of clarifying questions. If at any time, the conversation veers off track, members are expected to recognize it, and to call out each other. Otherwise, it can be construed as a poor use of the working member's set amount of time.

Each member's work concludes at the member's discretion, or when time has elapsed and the member does not request more. When all members who asked to work have finished, the next phase of the meeting, "Strokes," begins. During this time, members share specific compliments for others in the group, or announce each other's accomplishments. A key rule of "strokes" is that each compliment cannot be met with self-deprecation or devaluation in any way. It is required that each member accept the compliment or congratulations, and even better, respond with enthusiasm at the achievement. This last has proven to be very difficult for many members of Group.

The Group meeting rules have proved to be effective. More than once over the past few years, it has been brought up during "paranoias and held feelings" that the rules were not being strictly held, and that Group members found that Group was becoming less effective as a result.

\section{Discussion Themes}

Throughout Group's seven years of existence, many different topics have been discussed during the work portions of the meetings. To maintain the confidentiality of Group's discussions, this paper will not articulate specific examples of topics but will discuss general themes.

When the group began, many discussions were focused on classroom management. As early career faculty, few members of the group had significant amounts of classroom experience. But as faculty in STEM, members were aware of larger initiatives such as those to increase active learning in classrooms. This group served as a place to plan out or talk through course changes and classroom activity plans. Additional topics that were discussed frequently when the group first formed were: how to organize a research group; time management to balance short term needs with long term goals; how to recruit and mentor graduate students and postdoctoral assistants; and how to network within one's professional community. The group also discussed practical questions around navigating processes and procedures of the university.

Throughout the seven years of Group, the themes of the discussions have evolved. Classroom management, time management, and research group organization discussions are less frequent than they once were. Over the past three years most members of the group went through their respective version of promotion and/or tenure. During this period many discussions focused on creating promotion portfolios, specifics for demonstrating one's impact, and university procedures and policies related to promotion and tenure.

In the post-promotion phase of Group discussions have been increasingly focused on: navigating university politics; defining individual career success going forward; pivoting research to longer term and larger scale goals; managing larger teams; members' respective contributions to 
university leadership issues; and evaluating service obligations/opportunities to ensure they align with longer term goals.

\section{The Cohort Model}

Other models for faculty mentoring include those that are discipline-specific and those that focus on more senior colleagues mentoring junior (one of the authors, for example, has three assigned mentees among her departmental junior colleagues). Mentorship in other contexts is also not gender -specific. The specific approach of Group has been focused on mentorship among women across departments, schools and colleges, STEM affiliated, and at approximately the same point in their careers.

Group members observe some specific advantages to the cohort model. Being at the same point in our careers has meant that the primary themes of group have evolved with our careers and it is the rare piece of "work" that a member wants to do at a meeting that is not germane to most if not all of the other group members present. The interdisciplinary nature of Group has been particularly useful when issues of university policy are at stake. Department practice (or indeed departmental leadership preferences) are often presented (by accident or design) to junior faculty as campus-wide policy. It can be especially helpful to refer to best practice from other units or deeper knowledge of university procedure when engaged in any number of acts of self-advocacy or indeed advocacy for junior colleagues or graduate student mentees.

In addition to our varied departmental homes, Group members also serve in university level service positions across campus as senators, senate committee members and chairs, search committee members, and as members and leaders of committees for various institutional-level initiatives. The collective overview that this service provides to Group discussions has proved very useful.

\section{Outcomes}

Group members have been active and successful faculty members and librarians over the time that Group has been in place, and many of their successes would likely have happened in the absence of Group. There are however specific aspects of their time at Syracuse University that Group members identify as having been strengthened by their participation.

\section{Promotions}

Over the past six years, each member of Group has been promoted at least once, and those who were eligible for tenure have been awarded it. While the process of pursuing scholarly achievement ahead of review, choosing names to suggest for external letter writers, and preparing the dossier are inevitably stressful, the resources provided by being able to work in Group were invaluable. Members shared advice, anecdotes, and in some cases, full dossiers as examples.

In August 2016, Syracuse University created faculty member ranks for full-time non-tenure track faculty that focus solely on teaching (Assistant Teaching Professor, Associate Teaching Professor, or Teaching Professor) to facilitate longer term contracts and institute a process for 
promotion for non-tenure track faculty[7]. The expectations for teaching professors include excellent teaching in the classroom or laboratory and all the attendant tasks and qualifications. Teaching Professors are not expected to conduct research or engage with practitioners, but can so by choice extramurally. Their positions may also carry administrative duties and they are expected to participate in routine department, colleges, or university service. Two members of the Group were among the first Assistant Teaching Faculty members across campus to go through the new process. For these faculty, the group was an invaluable resource. Group members provided support specifically for putting together the promotion packages. Since this process was new, the members could prepare their documentation with support from tenure-track members, who guidelines were clearer. There was also a trusted support system for bouncing ideas off each other and planning. Finally, as with any professional advancement, the group always provided a space when needed for empathy, listening, care and encouragement, and ultimately, celebration when promotion was achieved.

\section{Professional Development}

Managing professional relationships is an integral part of an academic career, one for which most of us have little to no training. Fostering good working partnerships with graduate students and other group members, departmental and university faculty and staff colleagues, co-teachers, co-authors, external collaborators have all been frequent topics at Group. Specific strategies for dealing with building those relationships, addressing areas conflict, resolving difficult topics, and indeed, where necessary, ending those relationships have all featured over the years. Group members often report using a strategy or even specific language suggested by a fellow group member to improve their professional relationships.

Group members also actively and consciously serve to amplify each other's work across campus. When any group member receives an accolade or achieves a particular goal, it is celebrated with within and without Group. Introductions to new colleagues and championing of each other's abilities and successes where appropriate are integral aspects of Group.

Group has been particularly beneficial for members when it comes to academic writing. Group members have peer-reviewed each other's writing, particularly in cases where the members have previously written for, or been awarded funding from, the same or similar organizations/opportunities. Other mechanisms to support each other's writing has come in multiple forms of peer accountability: expecting reports on daily or weekly writing productivity; meeting for smaller "writing groups" where members use time together, often out of their offices if not entirely off campus, to make progress on writing projects. This comradery and accountability have specifically, and positively, affected almost every member of Group at some point.

\section{Collaborations}

In addition to providing support, mentorship and guidance in preparing Group member's individual grant applications, publications, and other initiatives, Group has also fostered new collaborations among members. Group members have written grants together and co-authored papers. Syracuse University is engaged in an expansion of the faculty driven by an interdisciplinary cluster hiring process. Pre-existing relationships from Group have been at the core of several of those clusters and group members are currently advocating for the hiring of up to 18 new faculty members across 4 colleges and 8 departments. Group members have directly 
assisted one another with the graduate student recruitment process, have sat on each other's graduate student committees and have even hired each other's students.

\section{Personal Supports and Successes}

Though the primary goals and outcomes of Group are professional, Group has also been a source of personal supports and celebrations. Members of Group have welcomed additions to their families and experienced loss since the formation of Group. During these times, members have organized meal trains and other methods of support for each other. One member was called upon to structurally engineer the other into her wedding dress demonstrating the overlap of the personal and professional relationships that have flourished from Group.

\section{Conclusion}

Peer mentoring is a proven strategy to improve career outcomes for academic women. The group detailed here demonstrates the applicability of a multi-disciplinary cohort model for early to midcareer STEM-affiliated female faculty and staff. The structure and best practices outlined above have proven successful, and the model is very promising for broader deployment. Group members strongly advocate that early career academics form similar groups and report outcomes. Further work is necessary to test the applicability across large populations, longer timelines, and multiple institutions.

[1] E. Daniell, Every other Thursday: stories and strategies from successful women scientists. Yale University Press, 2006.

[2] L. J. Sax and K. N. S. Newhouse, "Disciplinary Field Specificity and Variation in the STEM Gender Gap," New Dir. Institutional Res., vol. 2018, no. 179, pp. 45-71, Sep. 2018.

[3] J. L. Smith et al., "Added benefits: How supporting women faculty in STEM improves everyone's job satisfaction,” J. Divers. High. Educ., vol. 11, no. 4, pp. 502-517, Dec. 2018.

[4] H. Blackburn, "The Status of Women in STEM in Higher Education: A Review of the Literature 2007-2017," Sci. Technol. Libr., vol. 36, no. 3, pp. 235-273, Jul. 2017.

[5] R. E. Steinpreis, K. A. Anders, and D. Ritzke, "The impact of gender on the review of the curricula vitae of job applicants and tenure candidates: A national empirical study," Sex Roles, vol. 41, no. 7-8, pp. 509-528, Oct. 1999.

[6] K. A. O’Meara, G. Nyunt, L. Templeton, and A. Kuvaeva, "Meeting to transgress: The role of faculty learning communities in shaping more inclusive organizational cultures," Equal. Divers. Incl., vol. 38, no. 3, pp. 286-304, Apr. 2019.

[7] Syracuse University, "2.23 Timing of Promotions," Faculty Manual. [Online]. Available: https://provost.syr.edu/faculty-manual/2-1-faculty-and-academic-staff/. [Accessed: 03Feb-2020]. 